\title{
High spatial and temporal myocardial CINE T2* mapping at 7.0 T: a feasibility study
}

\author{
F Hezel $^{1^{*}}$, C Thalhammer ${ }^{1}$, S Waiczies ${ }^{1}$, J Schulz-Menger ${ }^{2,3}$, T Niendorf ${ }^{1,2}$ \\ From 16th Annual SCMR Scientific Sessions \\ San Francisco, CA, USA. 31 January - 3 February 2013
}

\section{Background}

Myocardial tissue characterization using T2* relaxation mapping techniques is an emerging application of clinical cardiovascular magnetic resonance imaging. The increase in microscopic susceptibility at higher magnetic field strengths renders myocardial T2* mapping at ultrahigh magnetic fields conceptually appealing. This work demonstrates the feasibility of myocardial $\mathrm{T} 2 \%$ imaging at $7.0 \mathrm{~T}$ and examines the applicability of temporally-resolved and high spatial resolution myocardial T2* mapping.

\section{Methods}

Imaging was conducted using a 7.0 $\mathrm{T}$ whole body MR scanner (Magnetom, Siemens Healthcare Erlangen) together with a 16 channel TX/RX coil array on 8 healthy subjects without any known history of cardiac disease. 9 CINE datasets were acquired with echo times ranging from $2.04 \mathrm{~ms}$ to $10.20 \mathrm{~ms}$ with a interleaved multi-shot multi-echo gradient echo technique over three breath holds. Other imaging parameters were set to: flip angle $=20^{\circ}$, acquisition data matrix $=256 \times 224, \mathrm{FOV}=(288 \times 252) \mathrm{mm} 2$, in-plane resolution $=(1.1 \times 1.1) \mathrm{mm} 2$, slice thickness $=4 \mathrm{~mm}$ and acceleration using GRAPPA ( $\mathrm{R}=3$ ). Prior to T2* mapping, volume selective $\mathrm{B} 0$ shimming was conducted to reduce static magnetic field inhomogeneities.

\section{Results}

After volume selective shimming, a mean peak-to-peak B0 difference of approximately $80 \mathrm{~Hz}$ was found across the entire heart for a four chamber view and a mid-ventricular short axis view of the heart (Fig1). The through plane field gradient at the myocardium/epicardial fat/lung interface was found to be much more pronounced versus the through-plane field gradient obtained for the left and right ventricle as illustrated in Fig. 1 . The latter showed a mean of $3 \mathrm{~Hz} / \mathrm{mm}$, which translates into an through-plane B0 dispersion of approximately $12 \mathrm{~Hz} /$ voxel for a $4 \mathrm{~mm}$ slice thickness. This B0 gradient implies that macroscopic intravoxel dephasing effects are of minor effect for the TE range used.

No severe susceptibility artifacts were detected in the septum and in the lateral wall for $\mathrm{T} 2 *$ weighting. For $\mathrm{TE}>7 \mathrm{~ms}$, a signal void (related to susceptibility weighting) was observed within the anterior and inferior myocardial segments. The longest $\mathrm{T} 2 *$ values were found for anterior $\left(\mathrm{T} 2^{*}=14.0 \mathrm{~ms}\right)$, anteroseptal $\left(\mathrm{T} 2^{*}=17.2 \mathrm{~ms}\right)$ and inferoseptal $(\mathrm{T} 2 *=16.5 \mathrm{~ms})$ myocardial segments. Shorter $\mathrm{T} 2 *$ values were observed for inferior $\left(\mathrm{T} 2^{*}=10.6 \mathrm{~ms}\right)$ and inferolateral $(\mathrm{T} 2 *=11.4 \mathrm{~ms})$ segments. A significant difference $(\mathrm{p}=0.002)$ in $\mathrm{T} 2 *$ values was observed between end-diastole and endsystole as illustrated in Figure 2. T2* changes of up to approximately $27 \%$ were observed across the cardiac cycle. Cardiac cycle dependent $\mathrm{T} 2 *$ changes were pronounced in the septum.

\section{Conclusions}

Our results underscore the challenges of myocardial T2* mapping at 7.0 $\mathrm{T}$ due to the propensity to macroscopic susceptibility artefacts and $\mathrm{T} 2 \%$ shortening, but demonstrate that these issues can be offset by using tailored shimming techniques together with dedicated acquisition schemes. 

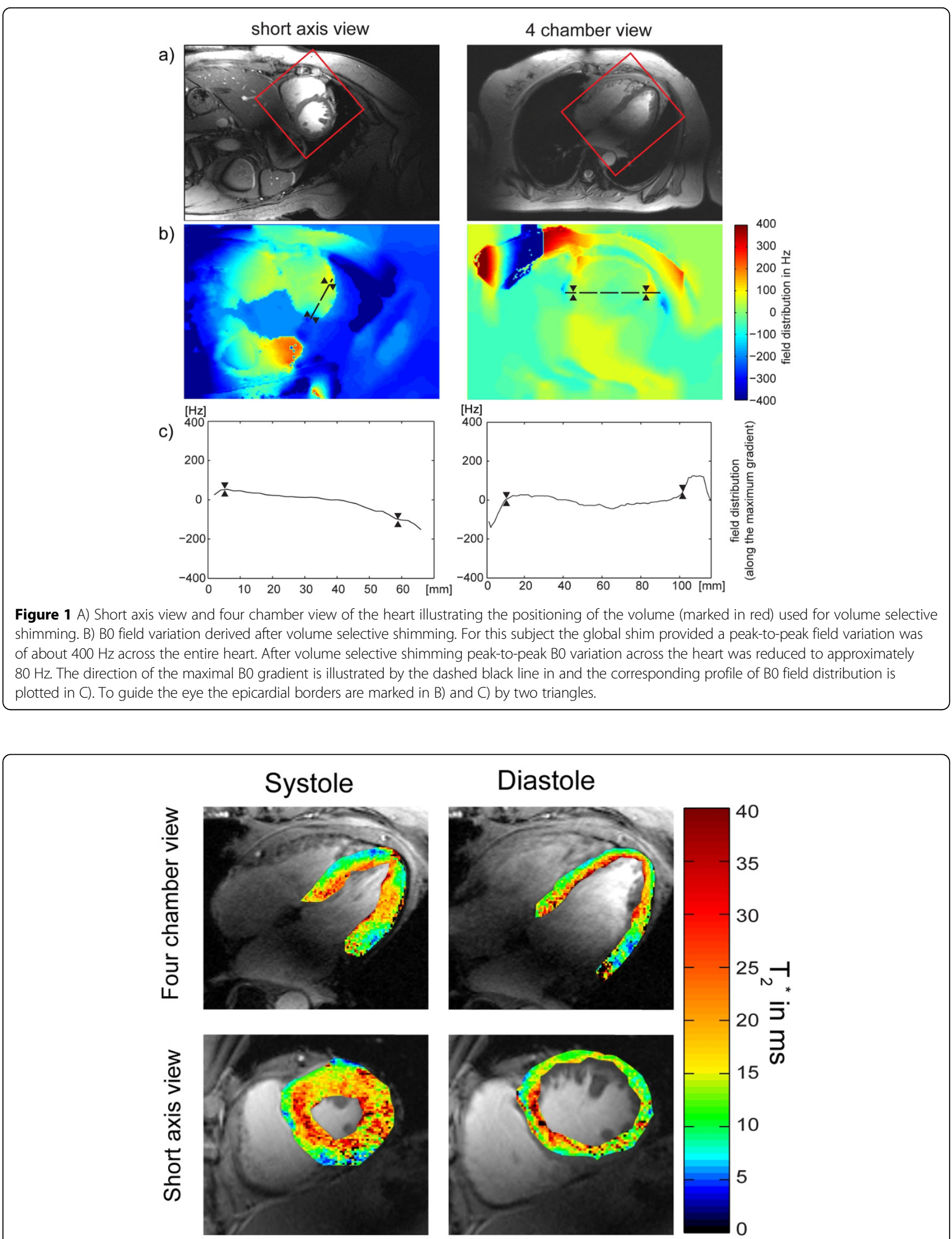

Figure 2 Four chamber (top) and short axis view T2* colour maps obtained from CINE T2* Mapping superimposed to anatomical 2D CINE FLASH gray scale images. Systolic and diastolic T2* maps show significant differences. 


\section{Author details}

${ }^{1}$ B.U.F.F., MDC Berlin, Berlin, Germany. ${ }^{2}$ Experimental and Clinical Research Center, a joint cooperation between the Charité Medical Faculty and the Max Delbrueck Center for Molecular Medicine Campus, Berlin, Germany. ${ }^{3}$ Department of Cardiology and Nephrology, HELIOS Klinikum Berlin Buch, Berlin, Germany.

Published: 30 January 2013

doi:10.1186/1532-429X-15-S1-W29

Cite this article as: Hezel et al: High spatial and temporal myocardial CINE T2* mapping at 7.0 T: a feasibility study. Journal of Cardiovascular Magnetic Resonance 2013 15(Suppl 1):W29.

Submit your next manuscript to BioMed Central and take full advantage of:

- Convenient online submission

- Thorough peer review

- No space constraints or color figure charges

- Immediate publication on acceptance

- Inclusion in PubMed, CAS, Scopus and Google Scholar

- Research which is freely available for redistribution

Submit your manuscript at www.biomedcentral.com/submit
() Biomed Central 